\title{
Филипская А.B.
}

Организация процесса обучения с использованием интерактивных технологий

МИРЭА - Российский технологический университет

(Россия, Москва)

doi: $10.18411 / \mathrm{j}-08-2021-59$

\section{Аннотация}

Авторы данной статьи рассматривают методику организации обучения иностранному языку с использованием интерактивных технологий. Рассмотрены признаки обучающей технологии. Показана значимость интерактивных технологий в обучении английскому языку. Проанализированы способы реализации интерактивных технологий на занятиях по иностранному языку.

Ключевые слова: интерактивные технологии, микроблог, приложение LinguaLeo, приложение Duolingo.

\section{Abstract}

The authors of this article consider the methodology of organizing foreign language teaching using interactive technologies. The signs of the training technology are considered. The importance of interactive technologies in teaching English is shown. The ways of implementing interactive technologies in foreign language classes are analyzed.

Keywords: interactive technologies, microblog, LinguaLeo application, Duolingo application.

Прежде чем рассматривать организацию обучения с использованием интерактивных технологий, следует отметить, что обучающая технология обладает рядом признаков:

- четкая, последовательная педагогическая, дидактическая разработка целей обучения, воспитания;

- структурирование, упорядочение, уплотнение информации, подлежащей усвоению;

- $\quad$ комплексное применение дидактических, технических, в том числе и компьютерных, средств обучения и контроля;

- усиление, насколько это возможно, диагностических функций обучения и воспитания;

- гарантированность достаточно высокого уровня качества обучения [2, c.61].

Обучающая технология находится во взаимосвязи с педагогическим мастерством. Педагогическое мастерство педагога состоит в том, чтобы отобрать необходимое содержание, применить подходящие методы и средства обучения, соответствующие программе и поставленным педагогическим задачам. Совершенное владение педагогической технологией и является педагогическим мастерством. Одна и та же технология может реализовываться разными педагогами, но в особенностях их осуществления как раз и проявляется их педагогическое мастерство [3, с.167].

В наши дни в процессе обучения применяются современные обучающие технологии, перед которыми стоит цель реализовать познавательную и творческую активность учащихся. Современные технологии дают возможность улучшить качество образования и более эффективно распределять учебное время. Современные образовательные технологии нацелены на индивидуализацию, дистанционность и вариативность процесса обучения, академическую мобильность учащихся, вне зависимости от возраста и объема знаний. 
Многие специалисты определяют современный этап развития образования как переход от устоявшихся массовых средств информации (фильмы, книги) к новым технологиям обучения, в частности интерактивным технологиям. Создание новых современных технологий обучения выступает необходимым условием для повышения мотивации и увеличения интереса студентов к изучаемой дисциплине, в нашем случае к иностранному языку, а также эффективности процесса обучения в целом. Изменения, которые внедряются в образовательный процесс, неразрывно связаны с технологическим прогрессом: развитием компьютерной техники и мобильных устройств, преимущества использования которых мы рассмотрим далее.

Особую значимость при организации интерактивного обучения иностранному языку приобретают мобильные устройства. На протяжении последних лет мобильные устройства, в первую очередь представленных в виде мобильных телефонов и планшетных компьютеров, не только все более широко используются, но и завоевывают все большую популярность, в первую очередь - у молодежи. Данные устройства стали сегодня фактически обязательной составляющей жизни современного человека. В ряде школ, в том числе высших учебных заведений, в отношении использования мобильных устройств налагаются ограничения и запреты. Но задача педагога состоит в том, чтобы сделать мобильные устройства своим союзником в обучении, т. к. применение данных устройств может быть связано не только с бытовыми, но и с образовательными целями.

В университетах ведущих стран мира учитываются возможности, которыми обладают мобильные устройства, основанные в первую очередь на платформах iPhone и Android, а также сайтов, оптимизированных под использование на данных устройствах. Данные возможности активно используются в ведущих вузах в рамках образовательного процесса. Они обеспечивают возможность студентам и иным пользователям сайтов посредством мобильных устройств узнавать университетские новости, пользоваться различными полезными ресурсами. В значительном числе зарубежных колледжей и университетов мобильные устройства применяются для того, чтобы облегчить и ускорить получение помощи по вопросам образовательного характера. К примеру, имеется возможность моментально получать информацию из библиотеки о наличии требующихся книг. Также многие образовательные учреждения предоставляют учащимся допуск к медиаплееру, что позволяет смотреть видеолекции и иные учебные материалы.

На современном этапе активно развивается дистанционное обучение, в рамках которого педагог взаимодействует с учащимися на расстоянии. Дистанционное обучение реализуется с использованием специальных образовательных средств, предусматривающих интерактивность. Указанное обучение реализуется, в частности, посредством использования мобильных устройств. Используя данные устройства, студенты имеют возможность получать знания вне университета.

Мобильные устройства могут использоваться в качестве дополнения к реальным программам обучения. Применение мобильных устройств позволяет получать знания в любом месте согласно реальной программе обучения. В этой связи учащиеся имеют возможность учиться в любое удобное время, в любом месте. Следует отметить, что существуют специальные обучающие мобильные приложения, которые вводятся в образовательный процесс. К примеру, имеются приложения, содействующие учащимся в изучении астрономии, истории, географии, математики, иностранных языков.

В качестве наиболее популярных приложений для изучения иностранных языков выступают Mirai, LinguaLeo, Language Coach, Duolingo, и значительное число других. В основном указанные приложения обеспечивают пополнение словарного запаса учащихся.

Так, в LinguaLeo предусмотрена возможность пользоваться библиотекой аудио, видео и текстовых материалов; интерактивными тематическими курсами; личным словарем с озвучкой каждого слова; набором тренировок, включающих кроссворды, перевод слов, аудирование; тематическими глоссариями; журналом развития, 
отображающим прогресс (реальный и возможный) в изучении языка. При этом ряд приложений ориентирован как на работу с лексикой, так и на то, чтобы развивать письменные и произносительные навыки, а также фонематический слух.

Еще одно популярное приложение подобного типа - Duolingo, включающее значительное число письменных уроков и диктантов. При этом развитию разговорных навыков в данном приложении уделено сравнительно мало внимания. Данное приложение включает игровое дерево уроков. Также имеется словарный раздел, в котором можно отработать пройденные слова. За один курс обучающийся может выучить до 2000 слов. Для обучения в Duolingo применяется подход, который основан на оценке статистики. На каждом из этапов система запоминает вопросы, которые вызвали у пользователя затруднения, и сделанные ошибки.

Следует отметить преимущества мобильных библиотек, существующих в сети Интернет. В течение продолжительного периода доступ к академическим библиотекам мог быть получен только посредством их посещения.

Вследствие развития сети Интернет, повышению популярности персональных компьютеров, мобильных устройств, каждый желающий имеет возможность найти в сети Интернет любую онлайн библиотеку и посетить ее, физически находясь в любом месте. Сегодня значительное число ресурсов, которые ранее предлагались только в библиотеках, доступны и в электронной форме.

Одним из направлений использования мобильных устройств в образовательном процессе является проведение мобильных опросов. Применение систем реагирования, обеспечивающих возможность педагогам получать от учащихся ответы при проведении опросов в электронной форме, требует значительных финансовых затрат, порядка 1200 долл. в час. При этом использование имеющихся мобильных устройств позволяет свести затраты на проведение указанных опросов практически к нулю. Использование программ Mobile Messenger и Poll Everywhere, или просто сервиса SMS позволяет педагогам проводить разнообразные флэш-викторины с применением образовательных программ. Возможно использование мобильных устройств при тестировании, выполнении домашних заданий и их проверке.

Широкое распространение мобильных устройств делает использование сервиса микроблогов удобным и простым. В процессе работы в классе вовлечение в образовательный процесс каждого из студентов требует значительных усилий. Однако данная проблема легко решается в случае использования Твиттер. При использовании данного сервиса учащиеся, использующие мобильные устройства, ноутбуки, активно задают вопросы педагогу, оставляют комментарии. Преподаватели имеют возможность отвечать на вопросы в режиме онлайн, обеспечивая мгновенную обратную связь.

Таким образом, можно сделать вывод, что организация процесса обучения с использованием интерактивных технологий на сегодняшний день базируется на основе применения мобильных устройств, использование которых распространено и завоевывает все большую популярность. Возможности специализированных приложений повышают степень вовлеченности обучающихся в образовательный процесс, степень уверенности в себе, а также обеспечивают дополнительную мотивацию, стремление выразить свою точку зрения и желание участвовать в учебном взаимодействии при выполнении учебных заданий, в том числе и на основе использования микроблогов.

$$
* * *
$$

1. Андреев А.А. Некоторые проблемы педагогики в современных информационно-образовательных средах//Инновации в образовании. 2004. № 6. С. 98-113.

2. Беспалько В.П. Слагаемые педагогической технологии/ Беспалько В.П. М: - 1989

3. Буланова М.В. Педагогика и психология высшей школы: учеб. пособие для вузов /М.В. Буланова Топоркова. Ростов - на Дону; Феникс, 2002. - 539с.

4. Гальскова Н.Д. Современная методика обучения иностранным языкам. М.: АР КТИ, 2001. - С. 141.

5. Левитес Д.Г. Практика обучения: современные образовательные технологии. - М.: Ин-т практ. психологии, Воронеж, 1998. - С. 186-195. 